\title{
Impact of Emotional Intelligence on Emotional Labor Strategy: the Mediating Effects of General Self-Efficacy and Organizational Identification
}

\author{
Yan Zeng ${ }^{1,2}$, Xi Chen ${ }^{1,2}$, \\ ${ }^{1}$ Key Laboratory of Behavioral Science \\ Institute of Psychology, Chinese Academy of Sciences \\ ${ }^{2}$ University of Chinese Academy of Sciences \\ Beijing, China \\ e-mail: lisa378@sohu.com,chenx@psych.ac.cn
}

\begin{abstract}
The present study conducted questionnaire method by taking 240 samples from service industry employees to probe into the relations between EI, GSE, OI and ELS. The result shows that: 1) a significant positive correlation between EI and all dimensions of ELS; 2) significant mediating effect by GSE between EI and surface-acting, deep-acting and automatic-acting of emotional labor; 3) significant mediating effect by $\mathrm{OI}$ between EI and deep-acting and automatic-acting of emotional labor. In the last part, the theory and practical significance of the paper will be discussed.
\end{abstract}

Keywords-emotional intelligence; general self-efficacy; organizational identification; emotional labor strategy

\section{INTRODUCTION}

In a profession of intensive interpersonal interactions, emotional labor takes up a leading position in the work of an employee, exerting direct influence on the working condition and performance of individuals. Past studies were mostly focused on the relationship between emotional intelligence, emotional exhaustion and emotional labor, or the impact of emotional labor on job satisfaction, individual performance and organizational behavior, talking a lot of the mediating effect of emotional labor. By contrast, this paper is intended to analyze the influencing factors in emotional labor strategy of service industry employees, from the two aspects of individual features and individuals' perception of the organization and based on studies of the relations among emotional intelligence, general self-efficacy, organizational identification and emotional labor strategy, providing practical reference for enhancing quality of emotional labor and HR management.

\section{A. Emotional Intelligence(EI)}

Goleman raised the concept of emotional intelligence, which refers to the ability of individuals in adaptively perceiving, understanding and regulating their own emotions and others', and in solving problems by utilizing emotions [1]. Law, Wong and Song defined four dimensions in the structure of emotional intelligence: self emotional appraisal, other's emotional appraisal, use of emotion and regulation of emotion [2]. Self emotional appraisal means that an individual is able to perceive and understand his own emotional state and naturally reveal his emotions. Other's

\author{
Yiwen Chen \\ Key Laboratory of Behavioral Science \\ Institute of Psychology, Chinese Academy of Sciences \\ Beijing, China \\ e-mail: chenyw@psych.ac.cn
}

emotional appraisal means an individual's ability of perceiving and understanding the emotions of those around him. Use of emotion means an individual's ability of activating his emotions to ensure active energy and performance. And regulation of emotion means despite a possible negative psychological state, an individual can still regulate and control his emotions well [3].

\section{B. Emotional Labor Strategy(ELS)}

Hockschild raised the concept of emotional labor, by which he believed that emotional labor refers to the efforts required by employees in regulating and managing their emotions. During emotional labor is conducted, employees should not only regulate their emotions in time but change emotional labor strategy based on the emotional response of the target of work, so as to maintain some proper interactive relationship [4]. The way and style of an employee in handling emotional events is emotional labor strategy [5].

Hochschild [4] proposed that typical emotional labor strategy includes surface-acting and deep-acting. Surfaceacting (or surface processing) stresses regulations of expression behaviors, like facial expression, posture, voice and tone and gesture, to make them comply with, in surface, the emotional display rules that an organization requires. Deep-acting (or deep processing) highlights adjusting perception of working environment and related requirements, so as to conform an individual's inner cognitive processing to the working emotions that an organization needs [6]. In addition to surface-acting and deep-acting, there's another mode of emotional work, namely, automatic-acting. During automatic-acting, an employee will naturally and honestly express the emotions he senses in the working environment, without need of paying efforts in regulating perception or expression behaviors [7].

\section{General Self-Efficacy(GSE)}

Self-efficacy is a concept raised by US psychologist Bandura, meaning that "people's faith in accomplishing a task or work behavior, involving not only their technical abilities but their confidence in completing work behaviors with the abilities they hold" [8].

Bandura defined three layers of self-efficacy: taskspecific self-efficacy, meaning the self-efficacy specifically for a certain task; domain-specific self-efficacy, meaning the self-efficacy specially for a certain domain of tasks; 
general self-efficacy, meaning the self-efficacy with which an individual handles challenges from all kinds of environment [8]. As the study selected research objects from different professional fields in the service industry, it's more accurate to utilize general self-efficacy as the research variable.

\section{Organizational Identification(OI)}

Freud was the first one to define "identification" as the emotional bond between an individual and others [9], and later Patchen applied it to organizational research, advancing the concept of organization identification [10]. Judging from the viewpoint of social identification theory, organizational identification means "a state where an individual defines himself according to his identity as a member of a specific organization, or a perception of belonging to a community". With higher degree of identification with an organization, an individual will be more likely to think from the perspective of the organization or conduct behaviors favorable for the organization, including more cooperation behaviors and organizational citizenship behavior [11].

\section{E. Research Hypothesis}

It can be known from the definitions of EI and emotional labor that while conducting emotional labor, an individual must regulate his emotions. Extant studies also find out the positive effect EI has on deep-acting of emotional labor will be stronger than that effect it exerts on surface-acting [12], thus we propose H1: a significant positive correlation can be found between EI and all dimensions of ELS.

Extant studies find out that significant positive correlation can be found between EI and GSE [13], significant positive correlation can be found between GSE and all dimensions of ELS [14], thus we propose H2: significant mediating effect is played by GSE between EI and all dimensions of ELS.

Extant studies find out that, a sentimental character has significant influence on OI [15], and the sentimentality is an emotional expression of individuals, a significant positive correlation can be found between OI and deep-acting of emotional labor [16], thus we propose H3: significant mediating effect is played by OI between EI and all dimensions of ELS.

\section{RESEARCH METHOD}

\section{A. Sample}

The study adopts the questionnaire method, targeted at the service industry. Research targets include salesmen, telephone operators, customer service staff, manager and director. The duration time for questionnaire collection is from January to February 2014, with 245 questionnaires returned in all, among which 240 are valid, taking up $98 \%$. The male makes up $48.75 \%$ of the total samples, while the female $51.25 \%$; those with an education background not higher than undergraduate course take up $46.25 \%$ of the total samples, and those with an education background not lower than master's degree take up 53.75\%; and those engaged in the trade for not more than 5 years take up $62.08 \%$, while those for not less than 6 years take up $37.92 \%$.

\section{B. Measuring}

All items adopt a scoring method of Likert 5 point scale.

\section{1) Wong and Law Emotional Intelligence Scale} (WLEIS).

This questionnaire drafted by Wong \& Law (2004) consists of 4 dimensions: self-emotional appraisal, other'semotional appraisal, use of emotion, and regulation of emotion; its reliability coefficient reaches 0.86 [2].

2) Emotional Labor Scale (ELS)

Drafted by Diefendorff (2005), used to appraise the expression strategy of emotional labor, lying in 3 aspects: the surface-acting made up of 7 items; the deep-acting made up of 4; while automatic-acting made up of 3 . The reliability coefficient reaches 0.79 [17].

3) General Self-Efficacy Scale (GSES)

Drafted by Schwarzer et al. (1997), featuring a coefficient of internal consistency of 0.87 ; the test-retest reliability is 0.83 , and the split-half reliability is 0.9 [18].

\section{4) Organizational Identification Scale(OIS)}

The scale developed by Mael and Ashfouth (1992) is used to measure OI, with a reliability coefficient of 0.81 [19].

\section{RESULT}

\section{A. Scale Reliability Test}

The scales applied in this study, after reliability analysis by Cronbach coefficient of internal consistency (a coefficient), prove to make the questionnaire of high reliability $(\alpha=0.94)$. And the reliability degrees of different scales are high. The result is in Table 1.

\section{B. Correlation Analysis}

The study firstly adopts correlation analysis to discuss the relations among variables. The result is in Table 1.

TABLE I. MEANS, STANDARD DEVIATIONS, COEFFICIENT ALPHAS AND CORRELATIONS OF EI, GSE, OI AND ELS

\begin{tabular}{|c|c|c|c|c|c|c|c|c|c|c|c|}
\hline 。 & $M$ & $S D+1$ & 2 & 3 & 4 & 5 & 6 & 7 & 8 & 9 & 10 \\
\hline 1Self Emotional Appraisal & $0.76+3.72$ & 0.70 & . & . & - & . & + & . & . & . & . \\
\hline 2 Other's Emotional Appraisale & $0.72=3.65$ & $0.65+.62 *$ & 0 & . & e & . & . & - & - & . & . \\
\hline 3 Regulation Of Emotion & $0.78+3.58$ & $0.69+64^{* *}$ & $.67 \%$ & D. & . & . & + & . & . & . & . \\
\hline 4 Use Of Emotion & $0.80=3.76$ & $0.73+.67^{* *}$ & $.67 *$ & $-67 *=$ & e. & . & e & e & - & - & e \\
\hline 5 General Self-Efficacy & $0.89=3.60$ & $0.63 * .57^{* *}$ & $.64^{*}$ & $.65^{*}$ & $0.64 *$ & & ? & - & . & . & e \\
\hline 6 Organizational Identification & $0.87 \% 3.78$ & $0.740 .60^{* *}$ & $.57 \%$ & $0.58 \%$ & $0.63 \%$ & $66^{\circ} \mathrm{0}$ & . & . & . & . & . \\
\hline 7 Surface-Acting & $0.81 * 3.11$ & $0.79+15$ & $14^{*}$ & $.15^{\circ}$ & $.13^{*}$ & $36^{+4}$ & $19 *$ & 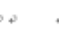 & . & . & 。 \\
\hline S Deep-Acting & 0.7503 .450 & $0.84,34 *$ & $35^{*}$ & $0.31{ }^{\circ}=$ & $0,43 \cdot 0$ & $.49 \%$ & $.42^{*}$ & $.54 \%$ & 。 & 0 & ? \\
\hline 9 Automatic-Acting & $0.60+3.480$ & $0.77+21 *$ & $22 *$ & د. & $29 \%$ & $46^{\circ}$ & $35^{* *}$ & $29 \%$ & & & s \\
\hline 10 Emotional Intelligences & $0.91+3.68$ & $0.60+.85^{* *}+$ & $.85^{*}$ & $.86^{\circ}$ & $.88^{*}$ & $.72^{+*}$ & $.69^{* *}+$ & .16 & $.42 *$ & $.266^{\circ}$ & $\infty$ \\
\hline
\end{tabular}


significant positive correlation can be found between EI and GSE; 3) a significant positive correlation can be found between GSE and all dimensions of ELS; 4) a significant positive correlation can be found between EI and OI; 5) a significant positive correlation can be found between OI and all dimensions of ELS.

Therefore, Hypothesis 1 is full established.

\section{Regression Analysis}

1) Test of the mediating effect of GSE on all dimensions of ELS

According to the definition and standard of mediating variable, regression analysis is conducted as to GSE, EI and all dimensions of ELS, so as to test whether GSE plays a full mediating effect or partial mediating effect. After testing and analysis, the result is shown as follows in Table 2.

TABLE II. REGRESSION ANALYSIS: THREE DIMENSIONS OF ELS AS A FUNCTION OF EI,GSE

\begin{tabular}{|c|c|c|c|c|c|c|c|c|c|}
\hline \multirow{2}{*}{$\begin{array}{c}\text { Variable and Factor } \\
\text { Step }\end{array}$} & \multicolumn{3}{|c|}{ Deep-Acting } & \multicolumn{3}{|c|}{ Surface-Acting } & \multicolumn{3}{|c|}{ Automatic-Acting } \\
\hline & 1 & 2 & 3 & 10 & 2 & 3 & 1 & 2 & 3 \\
\hline Gender & .01 & .06 & .06 & -.02 & .00 & .01 & -.00 & .03 & .03 \\
\hline Years of Working & -.04 & .08 & -.07 & .02 & .01 & .01 & .02 & -.00 & .00 \\
\hline Educational Background & $.27^{+* *}$ & .10 & .12 & .11 & .04 & .06 & $.18^{* *}$ & .08 & .10 \\
\hline Emotional Intelligence & s & $39 \cdots$ & .09 & . & $.15^{\circ}$ & $-23^{*}$ & s & $.23^{*}$ & $-19^{*}$ \\
\hline general self-efficacy & 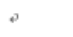 & 。 & $.39^{* \cdots}$ & 。 & . & $.50^{\circ \cdots}$ & 0 & . & $.57^{\cdots \cdots}$ \\
\hline$R^{2}$ & .08 & .20 & .27 & .01 & .03 & .15 & .03 & .08 & .23 \\
\hline$\triangle R^{2} \rho$ & $.08 \cdots$ & $.12 \cdots$ & $.07^{\cdots \cdots}$ & .01 & $.02^{\circ}$ & $.12 \cdots$ & .03 & $.04^{*}$ & $16^{\cdots}$ \\
\hline
\end{tabular}

Note: $p<0.05, " p<0.01, "{ }^{\prime} p<0.001$.

Based on the results above, we analyze the mediating effect played by GSE between EI and all dimensions of ELS, by using the method of multiple hierarchical regression. The gender, years of working and educational background, as control variables, are included in the equation in step one; then comes EI; lastly, GSE for analysis.

The result is shown in Table 2, indicating that educational background exerts certain predictive effect on deep-acting, but not significant predictive effect on surfaceacting and automatic-acting; and the gender and years of working have no significant predictive effect on all dimensions of ELS; GSE exerts a full mediating effect between EI and deep-acting, partial mediating effect between EI and surface-acting, partial mediating effect between EI and automatic-acting.

Therefore, Hypothesis 2 is full established.

2) Test of the mediating effect of OI on all dimensions of ELS

According to the definition and standard of mediating variable, regression analysis is conducted as to all dimensions of OI, EI and ELS, so as to test whether OI plays a full mediating effect or partial mediating effect. After testing and analysis, the result is shown in Table 3.
TABLE III. REGRESSION ANALYSIS: THREE DIMENSIONS OF ELS AS A FUNCTION OF EI,OI

\begin{tabular}{|c|c|c|c|c|c|c|c|c|c|}
\hline \multirow{2}{*}{$\begin{array}{c}\text { Variable and Factor } \\
\text { Step }\end{array}$} & \multicolumn{3}{|c|}{ Deep-Acting } & \multicolumn{3}{|c|}{ Surface-Acting } & \multicolumn{3}{|c|}{ Automatic-Acting } \\
\hline & lo & 20 & 30 & 10 & 20 & 30 & 10 & 20 & 3 \\
\hline Gender & .01 & .06 & .07 & -.02 & .00 & .01 & -.00 & -.03 & .050 \\
\hline Years of Working & .04 & .08 & -.08 & .02 & .01 & .00 & .02 & -.00 & .010 \\
\hline Educational Background & $.27^{\cdots \cdots}$ & .10 & .10 & .11 & .04 & .04 & $18^{* *}$ & .08 & .07 \\
\hline Emotional Intelligence & 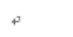 & $39 \cdots$ & $.21^{\circ}$ & ? & $.15^{\circ}$ & .04 & ? & $.23 *$ & .01 \\
\hline Organizational Identification & 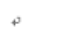 & . & $.27^{*}$ & 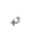 & 。 & .16 & 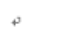 & 。 & $.33^{\cdots}+$ \\
\hline$R^{2}$ & .08 & .20 & .23 & .01 & .03 & .04 & .03 & .08 & .13 \\
\hline$\Delta R^{2 s}$ & $.08^{* * *}$ & $.12 \cdots$ & $.04 *$ & .01 & $.02^{\circ}$ & .01 & .03 & $.04 *$ & $.06 \cdots$ \\
\hline
\end{tabular}

Note: $p<0.05,{ }^{* x} p<0.01,{ }^{* x} p<0.001$

Based on the results above, we analyze the mediating effect played by OI between EI and all dimensions of ELS, by using the method of multiple hierarchical regression. The gender, years of working and educational background, as control variables, are included in the equation in step one; then comes EI; lastly, OI for analysis.

The result of regression is shown in Table 3, indicating that educational background exerts certain predictive effect on deep-acting, but no significant predictive effect on surface-acting and automatic-acting; and the gender and years of working have no significant predictive effect on all dimensions of ELS; OI exerts a partial mediating effect between EI and deep-acting, full mediating effect between EI and automatic-acting, but no significant mediating effect between EI and surface-acting.

Therefore, Hypothesis 3 is partially established.

\section{DISCUSSION}

\section{A. Relationship between EI and ELS}

EI probes into individual abilities in perceiving, managing and applying emotions. During the process of emotional labor, individuals need to regulate emotions to present emotional display rules that meet organizational requirements. EI is sure to be applied during the process of emotional labor. Therefore, EI has a significant predicative effect on all dimensions of ELS.

\section{B. The Mediating Effect of GSE between EI and ELS}

With higher level of the ability in perceiving, managing and applying one's own emotions and other's emotions, an individual will hold higher ability in regulating emotions and leading active vigor and performance, and will have more confidence in completing his jobs, thus more able to cope with and handle challenges of the environment and accomplish emotional labor according to organizational needs. Therefore, GSE has a significant mediating effect between EI and all dimensions of emotional labor.

\section{The Mediating Effect of OI Between EI and ELS}

With the ability of correctly perceiving one's own emotions and other's emotions, and in managing self emotions, an individual will see fewer opportunities in conflicting with other organizational members, and help shape a favorable organizational atmosphere, which will promote individual OI. With higher degree of OI, an 
individual will be more likely to identify with organizational rules, to actively regulate his mental state and behavioral way, so as to comply with the emotional display rules that an organization requires and conduct emotional labor. Therefore, OI has a significant mediating effect between EI and deep-acting, automatic-acting of emotional labor.

\section{Practical Implications}

The study provides certain enlightenment to HR management in the service industry. Past studies featured no scholars paying attention to the relationship between EI and OI. This study finding shows that it's possible to raise the OI of employees via training individual EI, thus providing new perspectives for HR management relying on the organization. In addition, an organization can reduce the negative influence of emotional labor on employees through training emotional perception, management and application in employees; through enhancing OI of employees, they can voluntarily regulate their mental states and behavioral patterns to meet organizational requirements; through promoting GSE of employees, their confidence in conducting emotional labor can be reinforced, so that the activeness and quality of emotional labor of service industry employees can be heightened.

\section{E. Limitations and future research}

There're two shortcomings about the study. Firstly, the objects of the study are only from Beijing, not concerning enterprises of other regions, thus of a small range; secondly, due to few studies about relationship between EI, GSE, OI and ELS, and their mechanisms of action in the past, the conclusion about the mediating effects that GSE and OI play between EI and ELS must be further verified in future studies.

\section{CONCLUSION}

The study is intended to present the relations among EI, GSE, OI and ELS, with the following conclusion: 1) a significant positive correlation can be found between EI and all dimensions of ELS; 2) significant mediating effect played by GSE between EI and surface-acting, deep-acting and automatic-acting of emotional labor; 3) significant mediating effect played by OI between EI and deep-acting and automatic-acting of emotional labor.

\section{ACKNOWLEDGMENT}

The corresponding author is Yiwen Chen, and his available e-mail is chenyw@psych.ac.cn.

\section{REFERENCES}

[1] Goleman D.Emotional Intelligence.New York: Bantam Books, 1995.

[2] Law K, Wong C, Song L. The construct and criterion validity of emotional intelligence and its potential utility for management studies. Journal of Applied Psychology, 2004,89(3): 483-496.

[3] Qin $\mathrm{Hu}$, Chen Yunzhe and Meng Hui. Relations among Emotional Labor, Emotional Intelligence and Job Burnout. Psychological Research, 2011, 4(1): 49-54.

[4] Hochschild, A. R. The managed heart. Berkeley:University of California Press.1983.

[5] Lin Chuan and Huang Miner. Impact of Trait Coping and Display Rules on Emotional Labor. Acta Psychologica Sinica, 2011, Vol. 43, No.1, 65-73.

[6] Brotheridge, C. M., \& Grandey, A..Emotional labor and burnout: comparing two perspectives of "people work".Journal of Vocational Behavior, 2002,60, 17-39.

[7] Ashforth, B. E., \& Humphrey, R. H.. Emotional labor in service roles: The influence of identity. Academy of Management Review, 1993, 18 (1), 88-115.

[8] Bandura,A. Self-efficacy: The exercise of control. New York: Freeman,1997.

[9] Freud S.Group Psychology and the analysis of Ego. New York: Norton, 1922.

[10] Patchen M.Participation,Achievement,and involvement on the Job.Englewood Cliffs,NJ:Prentice Hall,1970.

[11] Dutton J E.Dukerich J M.Harquail C V.Organizational images and member identification. Administrative Science Quarterly,1994,39:239-263.

[12] Wang Lu, Tang Chaoying and Gong Shaoyun. Relations among Emotional Intelligence, Motivation and Emotional Labor for Service Industry Employees. Economic Management Journal, 2009 (1).

[13] Huang Yingxi. Study of Relations among Emotional Intelligence, Self-efficacy and Professional Commitment, 2012.

[14] Bai Lili. Impact Study of Emotional Labor Strategy Selection on Organizational Effect, 2013.

[15] Mael,F\&Ashforth,B E. Alumni and their alma mater: a partial test of reformulated model of organizational identification. Journal of Organizational Behavior, 1992,(13):103-123.

[16] Yan Xiying. Study of Relations among Organizational Identification, Organizational Self-esteem and Emotional Labor. Human Resource Management, 2011.

[17] Diefendorff,J.M.,Croyle,M.H.,\&Gosserand,R.H.(2005).The dimensionality and antecedents of emotional labor strategies.Journal of Vocational Behavior,66,339-357.

[18] Schwarzer R,Babler J,Kwiatek P,Schroder K,Zhang J X. The assessment of optimistic self-beliefs:Comparison of the German,Spanish,and Chinese versions of the General self-efficacy Scale.Applied Psychology:An International Review,1997,46(1):69-88.

[19] Mael,F.,\&Ashforth,B.E.(1992).Alumni and their almamater: A partial test of the reformulated model of organizational identification. Journal of organizational Behavior,133,103-123. 